Cuadernos de Filología Clásica. Estudios Latinos

ISSN: 1131-9062

http://dx.doi.org/10.5209/cfcl.73008

\title{
El viaje al más allá en el Pelayo de López Pinciano: configuración clásica y alegoría cristiana
}

Jorge J. Linares Sánchez ${ }^{1}$

Recibido: 11 de mayo de 2020 / Aceptado: 23 de noviembre de 2020

Resumen: En el Pelayo de Alonso López Pinciano se relata el viaje al más allá del protagonista (libros décimo y undécimo). El héroe navega hasta Cilicia y desciende al inframundo por la gruta Coricia, donde, recibido por una divinidad metamórfica, se le revela el futuro y los arcanos del otro mundo. La ambientación de la aventura aúna la descripción de esta cueva en De Chorographia de Pomponio Mela y la de la morada del Sueño en las Metamorfosis de Ovidio. Se emula el patrón literario del tema del viaje al mundo de los muertos según los grandes modelos épicos, la Nékyia homérica y la catábasis de Eneas. Proponemos un análisis literario y comparativo de este episodio a fin de dilucidar cómo el Pinciano reelabora y combina estos referentes literarios y los adapta al contexto cristiano a través de la práctica de la alegoría, según los postulados presentados en su Filosofía antigua poética.

Palabras clave: Pinciano; Pelayo; literatura grecolatina; análisis comparativo; inframundo.

\section{[en] The journey to the otherworld in López Pinciano's Pelayo: classical configuration and Christian allegory}

\begin{abstract}
In Alonso López Pinciano's Pelayo the protagonist's journey to the otherworld is told (books 10 and 11). The hero sails to Cilicia and descends to the underworld through the Corycian Cave, where he is received by a metamorphic divinity. There he learns his future and the arcana of the beyond. The setting of the adventure combines the description of this cave in Pomponio Mela's De Chorographia and of the Dream's abode in Ovid's Metamorphoses. The literary pattern of the journey to the netherworld's theme is emulated according to the major epic models, the Homeric Nékyia and the katabasis of Aeneas. A literary and comparative analysis of the episode is proposed in order to elucidate how these literary references are reworked, combined and adapted to the Christian context by Pinciano through the practice of allegory, according to the postulates in his Filosofía antigua poética.
\end{abstract}

Keywords: Pinciano; Pelayo; Greek and Latin Literature; comparative analysis; underworld.

Cómo citar: Linares Sánchez, J. J. «El viaje al más allá en el Pelayo de López Pinciano: configuración clásica y alegoría cristiana», Cuad. Filol. Clás. Estud. Lat. 40.2 (2020), 271-290.

El doctor Alonso López, más conocido como López Pinciano o el Pinciano, fue uno de los humanistas más ilustres de su época. Su sobrenombre proviene de la ciudad de

Universidad de Murcia. Facultad de Letras. Departamento de Filología Clásica.

Correo electrónico: j1s12311@um.es 
Valladolid, considerada entonces la antigua $\mathrm{Pincia}^{2}$, donde habría nacido alrededor de 1547. En 1605 publicó el Pelayo, una epopeya sobre el primer monarca del reino de Asturias, considerado el iniciador de la posteriormente denominada «Reconquista». Unos años antes, en 1596, había visto la luz su Filosofía antigua poética, tratado de teoría literaria en forma epistolar que alcanzaría gran prestigio ${ }^{3}$. En la epístola undécima se recrea el diálogo que acerca de la epopeya mantuvieron el propio López Pinciano, Fadrique y Hugo. En ella el erudito vallisoletano establece la preeminencia de los poemas épicos clásicos, en especial la Eneida, como modelos a imitar, y traza los principales preceptos del género en torno a conceptos como la imitación, la ficción, la historia, la verosimilitud o la alegoría. El Pelayo supone el intento de Alonso López de llevar a la práctica estos postulados literarios.

La epopeya comienza tras la conquista de la Península por los musulmanes y la peregrinación de Pelayo, engañado por Lucifer bajo la forma del arcángel Uriel, a Tierra Santa. Allí se le aparece el verdadero Uriel, quien revela al héroe su misión divina como restaurador del imperio cristiano y le encomienda el regreso. Pero una tormenta enviada por el ángel caído hace naufragar el barco de Pelayo cerca de Chipre, donde es acogido por el rey Ayato y la princesa Adixa, ante quienes relata la caída del imperio godo y su travesía a Tierra Santa. Poco después, a instancias de Uriel, el héroe continúa su viaje, a pesar de los ruegos y amenazas de una enamorada Adixa, que sufrirá trágica muerte. Durante la navegación de vuelta a la patria, Pelayo arriba ante una misteriosa cueva que da acceso al más allá y allí se le profetiza el futuro como restaurador del cristianismo en España. Esto se cumplirá en los cantos siguientes, en los que se relata la llegada de Pelayo a Asturias, la batalla de Covadonga y la toma de Gijón, lo que marca el inicio de la Reconquista.

En el presente artículo se realiza un análisis literario y comparativo del tema del viaje al inframundo que se desarrolla en los cantos décimo y undécimo del Pelayo. Se analiza la ambientación del episodio y su relación con la información que el geógrafo latino Pomponio Mela ofrece sobre la región de Córica en De Chorographia. Posteriormente, se estudia cómo el Pinciano ha imbuido el episodio de connotaciones fantásticas y ctónicas, ausentes en Pomponio, mediante la comparación con otras fuentes clásicas, como las Metamorfosis de Ovidio, y con detalles de la doctrina cristiana. Finalmente, puesto que la aventura sigue el patrón literario del tema del viaje al más allá, se examina su argumento a tenor de las experiencias de ultratumba que Odiseo y Eneas acometieron en sus respectivas epopeyas.

El episodio se sitúa en la parte central de la epopeya (que consta de veinte cantos $)^{4}$, tras la estancia del héroe en Chipre y antes de su regreso a la Península. El argumento de la aventura es el siguiente: Poco después de partir del reino de Ayato, Pelayo hace una parada nocturna cerca de la ciudad de Córico, en la costa meri-

El Pinciano es también el sobrenombre de otro notable humanista vallisoletano, Hernán Núñez de Guzmán (conocido además como "el Comendador griego").

El tratado sigue la línea de la Poética de Aristóteles y de las doctrinas literarias de Tasso (Menéndez Pelayo 1940, 222-239; Vilanova 1953, 603-614; Lara Garrido 1982; Vilà 2005a; Maldonado Araque 2010).

$4 \quad$ La Nékyia en la Odisea y la catábasis de Eneas en la Eneida también se desarrollan en la parte central de su respectiva obra. La posición destacada del episodio del viaje al mundo de los muertos está motivada por su capacidad globalizadora y la significación heroica. Estas se originan por la ruptura en el más allá de los límites espaciales y temporales, lo que permite al héroe entrar en contacto con almas de lugares y épocas muy alejados, así como recibir profecías. De esta manera, en el inframundo el protagonista repasa el pasado a la vez que vislumbra el futuro (Linares Sánchez 2020, 25-30, 98-104 y 443-445). 
dional de la península de Anatolia. Se alza allí una altísima montaña, que se eleva hacía el cielo, y a sus pies yace la denominada Cueva Coricia, que penetra hasta las profundidades de la tierra. Pelayo se interna en la gruta $\mathrm{y}$, tras descender por tres lúgubres y terroríficas cavidades, llega a Cimeria, una extensa región subterránea. Aparece súbitamente una sombría alma que se metamorfosea en horrendas figuras a fin de asustar a Pelayo, pero este no se arredra. El guardián infernal, asombrado por su valor, le ofrece una breve profecía sobre su victoria en Asturias, con la que se iniciará la monarquía cristiana en España y Europa. A continuación, guía a Pelayo por las diversas regiones de Cimeria, cada una de ellas asignada a un hijo del Sueño: Fántaso, Ícelo y Morfeo. En la primera zona sufren mentirosos, como los sofistas, adivinos, alquimistas, supersticiosos o herejes; en la segunda son transformados en fieras los desobedientes, violentos, lascivos, glotones, avariciosos y otros pecadores incontinentes; finalmente, la tercera e idílica región está destinada a los bienaventurados, que gozan de una existencia común y justa en una ciudad divina. La noche se ha consumido en estas visiones y el guía de Pelayo desaparece con el alba. El héroe ha llegado ante dos puertas, una de cuerno y otra de diente, con un postigo mixto situado entre ambas. De la puerta de marfil salen tanto dioses grecolatinos (Urano, Ops, Vesta, Júpiter, los dioses olímpicos y otros muchos dioses y semidioses) como personajes de poemas épicos y novelas de caballerías (Perión, Amadís, Trebacio, Valerián, Primaleón, Palmerín, Olivante, Belianís, etc.); el postigo intermedio da salida a autores grecolatinos (Homero, Virgilio, Estacio u Ovidio) y a otros escritores presentes y futuros; atraviesan la puerta de cuerno las sombras de miles de gobernantes de todas las épocas pasadas, como los egipcios, asirios, medos, persas, griegos, romanos y godos. Apenado por la visión de Rodrigo, el último rey godo, el héroe Pelayo sale de Cimeria.

Al principio del episodio López Pinciano reelabora al detalle las especificaciones del geógrafo latino Pomponio Mela, que en De Chorographia describe la maravillosa gruta de Córico, junto a la ciudad del mismo nombre (1.13). Los paralelismos entre ambos textos son constantes. En primer lugar, se presenta el nombre de la cueva (supra specus est nomine Corycius, Mela.1.13.72; «Que Corica espelunca el mundo llama», Pelayo 10, f.135r) y su situación a los pies de una alta montaña. La gruta se ensancha a medida que se desciende; el visitante puede observar mejor su exuberante vegetación, que en un primer momento lo abruma, aunque después goza de tan bello espectáculo (Mela.1.13.72):

Tunc alte demissus et quantum demittitur amplior uiret lucis pendentibus undique, et totum se nemoroso laterum orbe conplectitur: adeo mirificus ac pulcher, ut mentes accedentium primo aspectu consternat, ubi contemplari durauere non satiet.

Entonces, profundamente hundida y más extensa cuanto más se hunde, verdea con arboledas colgantes por todas partes y se envuelve entera en el nemoroso círculo de sus paredes: es tan maravillosa y bella que a primera vista acongoja el ánimo de los que entran; y que, cuando se habitúan a mirar, no sacia 5 .

La traducción de los textos grecolatinos es propia. Puede consultarse la traducción anotada de la obra de Mela realizada por Guzmán Arias (1989). En cuanto a las ediciones de los textos clásicos utilizamos la de Frick (1880) para De Chorographia, Anderson (1962) para las Metamorfosis de Ovidio, el texto de la Eneida editado por Mynors (1972) y la edición de la Odisea de von der Mühll $\left(1962^{3}\right)$. 
López Pinciano da forma poética a las curiosidades orográficas ofrecidas por Pomponio Mela (Pelayo 10, f.135v):

En alto abierta da boca fruncida,

Que en baxo se dilata, y mas estiende (...).

Qualquiera que de alto vee la hondura,

De arboleda poblada que lo es de hoja,

Luego recibe vna mortal tristura,

Y siente en coraçón graue congoja:

Mas si el animo fixa, y ojo dura,

De tal manera la tristura afloja,

Que en vez del floxo espiritu rendido

Le entra consuelo de fabor crecido $^{6}$.

A través de un abrupto camino (descensus asper; «aspera baxada»), se accede a la primera de las tres concavidades, en la que se oye el sonido de aguas subterráneas (riuis hinc atque illinc fluitantibus, Mela.1.13.73; «aguas que de alto van caye[ $n]$ do»; Pelayo 10, f.136r). En la segunda oquedad un estruendo metálico produce gran pavor (MeLA.1.13.73):

Terret ingredientes sonitu cymbalorum diuinitus et magno fragore crepitantium.

Aterroriza a los que entran con el ruido de unos címbalos que resuenan sobrenaturalmente y con gran estruendo.

En el Pelayo se añade el detalle de que para soportar tal estruendo el visitante debe poseer también un corazón de metal, en particular de acero (Pelayo 10, f.136r):

Ruydo de metal suena espantable:

Para oyr sin pauor el cobre fiero,

Bien era menester pecho de azero.

Superado el miedo, se recorre un angosto, oscuro y largo túnel, por donde fluye un río que desaparece súbitamente entre las rocas (amnis ingenti fonte se extollens tantummodo se ostendit, et ... iterum demersus absconditur, MeLa.1.13.74; «Nace a dò, y muere subita corriente, / Que no puede alcançar no $[\mathrm{m}]$ bre de fue $[n]$ te», Pelayo 10, f.136r). El camino desemboca en la tercera concavidad, descrita en los siguientes términos (MeLa.1.13.74-75):

Intra spatium est magis quam ut progredi quisquam ausit horribile et ideo incognitum. Totus autem augustus et uere sacer, habitarique a diis et dignus et creditus, nihil non uenerabile et quasi cum aliquo numine se ostentat. 
Recorrer el lugar por dentro resulta más terrible de lo que nadie osaría y por ello es desconocido. Por lo demás, el conjunto, augusto y en verdad sagrado, se cree habitado por dioses y digno de ello; nada hay que no se muestre venerable y como acompañado de alguna divinidad.

De manera similar, el escritor hispano llama la atención sobre la creencia de que allí habitan los dioses y enfatiza la excepcionalidad de la aventura (Pelayo 10, f.136v):

Abrese despues desto el tercio seno,
Hoyo secreto, y hueco inacessible,
Seno profundo que de dioses lleno
A las credulas gentes fue creible:
Fondo terrible que qualquier terreno
En animo le pone vn impossible,
Y al hombre mas osado deste suelo
Derriba el coraçon, y enhasta el pelo.

Este territorio desconocido causa gran terror, pues es de naturaleza tan sobrecogedora que se considera morada de divinidades. ¿Quién osaría adentrase? Nuestro héroe, Pelayo, que, venciendo el temor, desciende el pavoroso camino y se introduce en la enigmática región.

Hasta este momento, siguiendo a Pomponio Mela, el caudillo ha caminado por una geografía real. Aunque ya en De Chorographia se comentaba su aura misteriosa, y el Pinciano, como veremos, amplía las características ultramundanas, en términos generales se describe un lugar auténtico. Sin embargo, una vez que Pelayo llega donde nadie antes había estado, el cambio de ambientación, de auténtica a fantástica, va acompañado de un cambio de fuente literaria. Para describir este nuevo más allá, López Pinciano toma como base la descripción de la morada del Sueño y de sus hijos en el libro undécimo de las Metamorfosis de Ovidio (11.592-601):

Est prope Cimmerios longo spelunca recessu, mons cauus, ignaui domus et penetralia Somni: quo numquam radiis oriens mediusue cadensue Phoebus adire potest; nebulae caligine mixtae exhalantur humo dubiaeque crepuscula lucis. non uigil ales ibi cristati cantibus oris euocat Auroram, nec uoce silentia rumpunt sollicitiue canes canibusue sagacior anser; non fera, non pecudes, non moti flamine rami humanaeue sonum reddunt conuicia linguae.

Hay cerca de los cimerios una gruta en un lugar muy apartado, un monte hueco, hogar y santuario del perezoso Sueño, donde nunca con sus rayos al salir o en lo alto o al caer puede Febo llegar; nubes mezcladas con niebla son exhaladas por la tierra y un crepúsculo de incierta luz. Allí ni la atenta ave de encrestada cabeza evoca 
a la Aurora con cantos, ni con su voz rompen los silencios

los agitados perros o el ganso más sagaz que los perros;

ni fieras, ni ganado, ni ramas movidas por el viento

o el alboroto de la lengua humana producen sonido.

El propio Ovidio, debido a la proximidad entre el sueño y la muerte, ha combinado en estos versos detalles del viaje al mundo de los muertos de la Odisea y de la Eneida. De la Nékyia procede la mención del pueblo de los cimerios y la imposibilidad del Sol de iluminar la región con sus rayos al alba o al ocaso (Od.11.14-19); del descenso de Eneas, la ausencia de aves por los vapores tóxicos exhalados de la gruta infernal (Aen.6.237-242). Ovidio, combinando la ambientación homérica y virgiliana, sitúa junto a los cimerios una gruta inaccesible a Febo cuya nociva neblina impide el paso a cualquier animal. Este veto a los animales favorece un silencio absoluto muy adecuado para la residencia del Sueño. López Pinciano recoge esta tradición en su ambientación de la maravillosa Cimeria ${ }^{7}$, cuyo nombre evoca el contexto de ultratumba de la Nékyia homérica y la naturaleza onírica de la región ovidiana. La ausencia de sonido es tal que ni Harpócrates, dios del silencio, la podría superar (Pelayo 10, f.137r-137v):

En margines de aquesta sorda ria

Tendida a todas partes se derrama

Debaxo de las tierras vna fria,

Que tierra de Cymeria el mu[n]do llama (...)

Aqui el silencio, y la mudeza tanta

$\mathrm{q}[$ ue $]$ a Harpocrates no dio par en su escuela

Aqui ni ladra can, ni gallo canta,

Ni pajaro jamas en ayre buela:

Y aqui la boz que arroja la garganta

Al punto retrocede, ò ya se hiela:

Escusan solamente los oydos

Resuellos espantables, y ronquidos.

Se recrea de esta manera una atmósfera propicia para las ensoñaciones de ultratumba. Según muestra el espíritu guía de Pelayo, una vez que este ha demostrado su valor ante sus horrendas transformaciones, Cimeria está dividida en tres regiones, cada una asignada a un hijo del Sueño (Pelayo 10, f.139v):

En tres pares porciones se reparte

La tierra que por nombre da $[n]$ Cymera,

Rige Fantàs las pecoras sin arte,

Faltas de lumbre en la estacio[n] primera:

Las fieras manda Icelo en otra parte,

Antes que López Pinciano, ya Tasso había recreado estos motivos en su Jerusalén Liberada, al describir una selva encantada con connotaciones infernales (13.9-24). El poeta italiano puebla la selva de plantas antiquísimas y horrendas, detalle que el Pinciano amplifica con una enumeración de vegetales (p. ej. nenúfar, junco, mandrágora, cicuta, beleño, lechuga o cebolla). 
Los hombres el Morfeo en la tercera:

Ver dixeras en Reyno assi diuiso

Vn Limbo, vn Purgatorio, y Parayso.

Para remarcar la naturaleza onírica de la aventura, el más allá no ha sido asignado a los tradicionales jueces de ultratumba (Minos, Radamantis y Éaco), sino a tres hijos del Sueño. De nuevo, el Pinciano ha bebido de la fuente ovidiana. El citado episodio de las Metamorfosis continuaba con la mención de las habilidades metamórficas de la prole del Sueño (11.633-643): Fántaso era capaz de transformarse en objetos inanimados, sin alma; Ícelo se convertía en animal; Morfeo podía tomar forma humana. López Pinciano aplica estos poderes a las características de las almas y las regiones que habitan. En la fría y estéril región de Fántaso penan las almas condenadas por su falta de entendimiento (en cierta manera, son cosificadas); Ícelo gobierna los espíritus de quienes, debido a su incapacidad de contenerse, son forzadas a adoptar la forma de diversos animales; Morfeo reina sobre los bienaventurados, que por su virtud habitan como humanos íntegros una ciudad celestial en una región idílica.

Como vemos, López Pinciano traza una ambientación grecolatina, pero apostilla que Cimeria podría considerarse dividida en «un Limbo, un Purgatorio y un Paraíso» $\rangle^{8}$. No se trata de un detalle baladí. A lo largo del episodio el autor vallisoletano desliza señales que sugieren que, bajo la onírica pátina de mitología grecolatina, se esconde un sólido contenido de doctrina cristiana. La descripción de la montaña de Córica está tomada de De Chorographia, pero a diferencia de Mela, que en ningún momento vincula la región con el más allá, el Pinciano especifica que esta llega con su cima al Cielo y hunde sus raíces hasta el Limbo. Esta concepción refleja la visión cristiana del más allá, que, por ejemplo, se desarrolla en la Divina Comedia, en la que el monte Purgatorio une el Paraíso con el Infierno. Coincide también con el poema italiano en sus condenados, que reflejan pecados de herejía, soberbia, ira, lascivia, gula, envidia o avaricia típicos del infierno cristiano?.

En suma, el marco de la acción ha sido constituido mediante la yuxtaposición de la descripción geográfica de la cueva Córica de Mela y la adaptación de motivos ovidianos acerca de la morada y la prole del dios del Sueño. De esta manera, se ha generado un paraje en el que la realidad enlaza con la fantasía y bajo el que subyace un contenido doctrinal cristiano acorde con las concepciones morales predominantes en la época de López Pinciano.

Con estos elementos como telón de fondo, se desarrolla en el episodio el patrón argumental característico del viaje al mundo de los muertos. En la epopeya occidental los dos grandes modelos clásicos del tema son la Nékyia (Hom.Od.11) y la

Por las palabras de López Pinciano podría colegirse que la región de Fántaso es el Limbo (o el Infierno) y la de Ícelo el Purgatorio. Sin embargo, la naturaleza de los pecados no se corresponde con esta concepción. Su organización proviene de la conceptualización de las propiedades de los hijos del Sueño: Fántaso simboliza a los pecadores mentales, cuyas almas son cosificadas por su vileza intelectual; a Ícelo pertenecen los espíritus animalizados por su incontinencia y exceso pasional.

9 López Pinciano no menciona nunca a Dante en la Filosofía antigua poética, lo que ha llamado la atención de la crítica. Véase Frutos Martínez (1999), que considera que en esta época «el prestigio de la poesía dantesca había sido asumida por Petrarca» (p. 346), que sí es citado por el vallisoletano. Este silencio, sin embargo, no invalida la posibilidad de que el autor del Pelayo, para dotar su más allá de un trasfondo cristiano, se haya inspirado en la obra italiana, que por otra parte habría ejercido un fuerte influjo en el imaginario colectivo sobre el más allá. 
catábasis de Eneas (Verg.Aen.6) ${ }^{10}$. La semejanza argumental de los tres episodios resulta patente.

En la Nékyia Odiseo navega a la entrada del inframundo, en cuyas inmediaciones se alza la ciudad de los cimerios, junto a bosques y ríos infernales. A pesar del temor que siente, rechaza a las almas con la espada hasta que un difunto adivino le ofrece una profecía acerca de su regreso a la patria y la victoria sobre quienes pretenden arrebatarle el trono. Además, observa un gran número de espíritus de héroes y heroínas, y a los condenados míticos.

En el descenso de la Eneida el caudillo latino navega a Cumas y se interna por una cueva en el inframundo. Superado su pavor, atraviesa las regiones del más allá, guiado por la Sibila, y observa a los difuntos, condenados y bienaventurados. El espíritu de su padre le muestra la futura gloria de Roma en la figura de las almas que nacerán de su linaje y vaticina los enfrentamientos bélicos en Italia. Eneas regresa por la puerta de marfil.

En el viaje onírico del Pelayo, el héroe navega a Cilicia y se adentra por una cueva hasta Cimeria, poblada de bosques y rodeada por un río infernal. Superado el temor, un alma metamórfica predice el regreso y la liberación de la patria, así como la fundación de un linaje regio y la futura gloria del reino hispano. Guiado por este ser, atraviesa las regiones del más allá, y observa a los pecadores y a los bienaventurados. En su regreso por la puerta de marfil, aparecen ante él un gran número de espíritus: dioses paganos, personajes caballerescos, escritores (Homero y Virgilio los primeros) y reyes.

Ciertos motivos y otros detalles literarios de la Nékyia, posteriormente reelaborados en la catábasis latina, llegaron a convertirse en elementos arquetípicos del tema. López Pinciano retoma y adapta esta dilatada tradición de raigambre clásica ${ }^{11}$.

Odiseo y Pelayo llegan en barco a la boca del más allá al anochecer ${ }^{12}$. Bajo una oscuridad muy apropiada para la inminente aventura de ultratumba, el inicio se

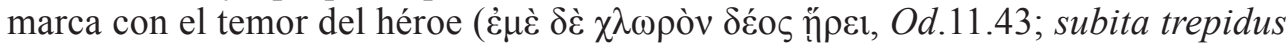
formidine, Aen.6.290; "Siente angustia mortal», Pelayo 10, f.137r). El protago-

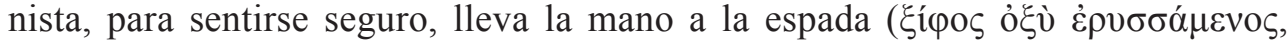
Od.11.48; Corripit ... ferrum / Aeneas, Aen.6.290-291; "puño en hierro pone», Pelayo 10, f.136v).

Superar este miedo comporta una gran recompensa, el conocimiento del futuro. Otro de los elementos característicos del tema es la obtención de una profecía en el mundo de los muertos, privilegio que sería posteriormente heredado y adaptado en

10 En la Filosofia antigua poética son constantes las alusiones y alabanzas de ambas epopeyas, cuya influencia se deja sentir en todo el Pelayo. El propio argumento de la obra, que relata el viaje marítimo de Pelayo de vuelta a su patria y los enfrentamientos bélicos por recuperarla, sigue de cerca el de la Odisea (regreso por mar de Odiseo y enfrentamiento armado con los pretendientes para recuperar el trono) y de la Eneida (navegación de Eneas a Italia y lucha para lograr su asentamiento). Además del viaje al más allá, otros episodios y escenas característicos de ambos poemas son emulados por el Pinciano, como el naufragio del héroe por una tormenta, la salvación a manos de divinidades marinas, el recibimiento por el rey de una ciudad idílica, el relato secundario de sucesos pasados durante un banquete, etc.

11 Multitud de autores de las diferentes etapas de la literatura occidental, como Silio Itálico, Dante, Ronsard, Lope de Vega o Fénelon, recrearon viajes al más allá con una base literaria grecolatina, a partir del modelo homérico y virgiliano (Linares Sánchez 2020).

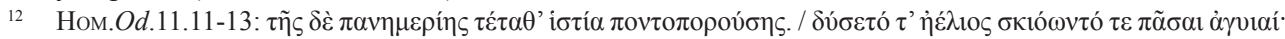

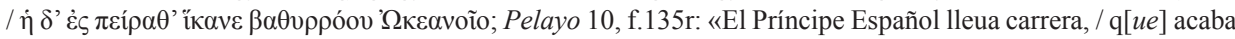
mientra el Sol passa al Ponie $[n]$ te». 
las novelas de caballerías, donde el vaticinio se recibe dentro de una cueva encantada. En el Pelayo se armonizan ambas tradiciones, pues el caudillo asturiano escucha su porvenir en una cueva encantada que ha sido transformada en un inframundo onírico $^{13}$. Allí aparece súbitamente el alma de un profeta metamórfico («Subito se aparece vna alma umbria», Pelayo $10, \mathrm{f} .137 \mathrm{v}$ ), lo que recuerda a la evocación del ánima

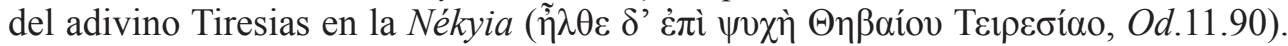
Como en la Odisea, la predicción del espíritu adelanta el regreso del héroe al hogar y su liberación de los invasores ocupantes. Pero a diferencia del conflicto personal del itacense, cuya lucha con los pretendientes carece de relevancia histórica, Pelayo afrontará una gesta nacional. Es el pedernal con el que prenderá la hoguera de la Reconquista y la hegemonía ibérica, el eslabón entre la monarquía goda y la realeza hispana (Pelayo 10, f.138v):
La Asturia libraras, y a Monarquia
Eterna prestaras alto cimiento:
Parte por el valor de valentia,
Y parte por virtud de testamento,
Al tuyo se vniran Reynos fecundos,
Reynos, no digo bien, no sino mundos.

En este sentido, la figura de Pelayo es similar a la de Eneas, hijo de Troya y ancestro de los gobernantes que convertirán Roma en una potencia mundial ${ }^{14}$. De hecho, siguiendo una disposición simétrica, el guía repite el vaticinio al final del libro y avanza que el imperio español superará al romano (Pelayo 10, f.149v):
Restauro prestaras a la ruina
De España q[ue] la traxo el Rey Rodrigo:
Por falta de consejo: tu le toma,
Y tu cetro serà mas que el de Roma.

Tras la profecía, el guía se dispone a mostrar a Pelayo los misterios del más allá. Se trata de una revelación arcana, sagrada, por lo que el autor debe pedir permiso a la deidad para proseguir su relato. López Pinciano ruega a la divinidad infernal licencia para desvelar los secretos que se esconden bajo tierra (Pelayo 10, f.139r):

Seame licito (ò Príncipe Cymerio,

Amigo de la paz, contrario a guerra)

Dar publico el secreto, y gran mysterio

Que de $[n]$ tro de tu Reyno ho[n]do se cierra.

Se trata de una petición similar a la que hiciera el poeta Virgilio siglos antes (Aen.6.264-267):

13 Cervantes hará algo semejante en el episodio de la Cueva de Montesinos en cuyo interior Don Quijote experimenta la ensoñación de un más allá caballeresco (Segunda parte, caps.22-23).

14 Epopeyas como el Pelayo fueron usadas para el ensalzamiento nacional en base al modelo virgiliano (Vilà 2005b, 2006 y 2007). 
Di, quibus imperium est animarum, (...)

sit mihi fas audita loqui, sit numine uestro

pandere res alta terra et caligine mersas.

Dioses que detentáis el imperio sobre las almas, (...)

Séame lícito expresar lo escuchado, séalo con vuestro beneplácito

revelar la materia sumergida en tierra y tiniebla.

Pero el Pinciano añade a continuación unos versos, ausentes en el modelo virgiliano, en los que se dirige al lector y declara el objetivo de la revelación, mostrar a los reyes y a sus súbditos exempla morales sobre el bien y el mal:

Vos, digo, que mandays, y que rendidos

Seruis con sujecion, en tres espacios

Vereys (si oys) por el exemplo ageno

La fuga, y secucion del malo, y bueno.

López Pinciano, que en su Filosofía antigua poética recomienda el uso de la alegoría en la epopeya, sugiere la lectura simbólica del episodio ${ }^{15}$. No hay que olvidar que, desde antiguo, se consideraba que los modelos de la épica, la Iliada, la Odisea y la Eneida, eran epopeyas alegóricas ${ }^{16}$. Precisamente, el significado simbólico excusa la ambientación pagana, pues el cuerpo grecolatino cobija un alma cristiana.

Esta doctrina cristiana emerge de las características morales de los pecadores y bienaventurados que habitan las tres regiones oníricas. Pelayo observa en su viaje una gran muchedumbre de almas, de las que el guía da las explicaciones pertinentes. Pero las sombras son tan numerosas que el ser metamórfico se declara incapaz de referirlas todas (Pelayo 10, f.142v):

Que esperas? si (varon) yo te dixesse

Los muchos, $\mathrm{q}[u e]$ del mundo va $[n]$ vinie $[n] \mathrm{do}$,

No dudo que la platica estendiesse

En numero sin numero creciendo:

A causa de ser tanto el interesse

La dadiua dificile suspendo,

Contento con te dar la cosa en suma,

Que no cabe sin ella en le[n]gua, y pluma.

Estamos ante una recusatio característica del tema del viaje al mundo de los muertos. En la Nékyia Odiseo expresa ante los feacios que «no podría decir ni nombrar» a todas las difuntas que vio; el relato se extendería tanto que «antes se consumiría la noche» (Od.11.328-330). Tampoco la Sibila sería capaz de contarle a Eneas el nombre y castigo de todos los condenados, ni siquiera si tuviera cien bocas y una

15 La primera edición contenía al final de la obra un apartado dedicado a la interpretación alegórica del Pelayo, en el que se especifica que la entrada del caudillo en la cueva Coricia significa la entrada del «justo en la de la Meditación».

16 Filosofia antigua poética 11, p.175: «Esta, pues, es la alegoría que en la épica se halla muy ordinariamente; de manera q[ue] la Ilíada y Odysea de Homero y la Eneyda está[ $n]$ llenas destas alegorías y ánimas intrínsecas». 
voz férrea (Aen.6.625-627) ${ }^{17}$. En los tres textos el narrador se siente abrumado ante tamaña empresa, pues los espíritus son innumerables.

El vicio de algunos de estos espíritus se plasma gráficamente, como las almas bestializadas de la región de Ícelo. La horrenda visión incita al héroe a atacarlas, pero el guía lo disuade (Pelayo 10, f.141r-141v):

Y a la alma que guiar quiere delante, Precede espada en mano el fuerte Infa $[n]$ te

Torna a la funda el reluciente azero

Dize la so $[m]$ bra al gran Principe Hispano,

$\mathrm{Ni}$ al rustico animal estes oy fiero,

$\mathrm{Ni}$ al humano te prestes tan tyrano:

Escucha: quanto vees con bruto cuero,

Otro tiempo vistio pellejo humano,

Humana piel gozo, y aun ser podria

Gozasse piel humana en algun dia.

Se trata de un nuevo motivo de ascendencia clásica. Ya en la Odisea el héroe rechazó a las almas con su espada para que no se acercaran al hoyo repleto de sangre sacrificial, pues Circe así lo había aconsejado (Od.11.48-50). Virgilio invierte el motivo, pues, aunque Eneas se dispone a atacar a unas sombras monstruosas, la advertencia de la Sibila de que son entes sin sustancia material lo detiene (Aen.6.291$294)^{18}$. López Pinciano modifica la causa de la advertencia: Pelayo debe abstenerse de atacarlas no por la inutilidad de tal gesto, sino porque su esencia humana merece compasión ${ }^{19}$.

En el caso de Eneas no resultaba oportuno recomendar clemencia. A diferencia de Pelayo, el héroe troyano no amaga contra espíritus humanos, sino contra las abstracciones del mal que pueblan la entrada del inframundo (Aen.6.273-281):

Vestibulum ante ipsum, primisque in faucibus Orci

Luctus et ultrices posuere cubilia Curae;

pallentesque habitant Morbi, tristisque Senectus, et Metus, et malesuada Fames, ac turpis Egestas, terribiles uisu formae: Letumque, Labosque;

tum consanguineus Leti Sopor, et mala mentis

Gaudia, mortiferumque aduerso in limine Bellum, ferreique Eumenidum thalami, et Discordia demens, uipereum crinem uittis innexa cruentis.

Ante el mismo vestíbulo y en las primeras gargantas del Orco

17 Se encuentran muestras similares de esta recusatio en la Divina Comedia de Dante (Infierno 4.145-147), África (1.583-584) y Triumphus cupidinis (1.148-150) de Petrarca, y Orlando furioso de Ariosto (3.23), entre otros.

18 Tanto la recomendación homérica de rechazar a los espíritus como la exhortación virgiliana en sentido contrario han sido reelaboradas en textos posteriores (p. ej. SiL.13.441-444, Roman d'Eneas 2502-2513 o Hesperis 9.194198).

19 El motivo se repite más adelante en la región de Morfeo. Pelayo se apresta a socorrer a una mujer acosada por un sátiro, pero el guía lo detiene («al braço frena, y al metal co[n]trasta», Pelayo 10, f.144v) porque ella se basta para rechazar a la lasciva criatura. 
el Dolor y las vengativas Preocupaciones poseen sus guaridas; y habitan las pálidas Enfermedades, y la triste Vejez, y el Miedo, y el Hambre que mal aconseja, y la fea Pobreza, figuras terribles de ver; y la Muerte y la Pena; además, el hermano de la Muerte, el Sueño, y de la mente los malos Disfrutes, y frente a la entrada la mortífera Guerra, y de las Euménides los férreos lechos, y la Discordia demente, ceñido su cabello de víboras con sangrientas ínfulas.

A esta enumeración se añade una serie de espíritus monstruosos: los centauros, las Escilas, los gigantes Briareo y Gerión, la Hidra de Lerna, la Quimera, la Gorgona $^{20}$ y las Harpías ${ }^{21}$.

Pelayo se libra de tan horrendo encuentro y llega a la ciudad divina en la región de los bienaventurados sin cruzarse con estos seres perversos ${ }^{22}$. Precisamente, para enfatizar la naturaleza idílica de la urbe de ensueño, se especifica que está exenta de abstracciones malignas y de monstruos (Pelayo 10, f.147r-147v):

No aqui la ociosidad engendradora

De fria desnudez, y hambre amarilla,

Ni mora el interes propio, y no mora

Por su ocasion en proximos rencilla:

No la necessidad persuadidora

Robusta al mal hazer, tiene aqui silla:

Falta el ocio mendigo en esta tierra,

Y con el la pobreza, el robo, y guerra.

No el çangano, ni buela aqui la harpia,

Ni rua inutil turba, y holgaçana...

Aunque López Pinciano invierte el catálogo virgiliano y lo convierte en un medio de exaltación de la ciudad bienaventurada, ambas enumeraciones comparten tanto algunos de sus elementos (Fames / Hambre, Discordia / Rencilla, Egestas / Pobreza, Bellum / Guerra, Harpyiae / Harpía) como las fórmulas introductorias (posuere cubilia / «tiene aqui silla», habitant / «mora»).

Con la visión de la ciudad celestial se completa la visita de las tres regiones del más allá. El libro décimo finaliza con la llegada del amanecer, que obliga al guía cimerio a marcharse. En el libro undécimo Pelayo emprende el ascenso y se encuentra frente a dos puertas, una de cuerno y otra de diente (f.151r-152r):

20 La gorgona Medusa es el único ser monstruoso que se menciona en la Nékyia. Ante el miedo de que Perséfone le envíe la cabeza de este petrificante ser, finaliza la experiencia nigromántica (Od.11.634-635).

21 Este catálogo de abstracciones malignas y de monstruos gozó de una gran tradición literaria en la literatura latina y en épocas posteriores: Hércules furens de Séneca (689-696), Púnicas de Silio Itálico (13.581-600), In Rufinum de Claudiano (1.25-40), África de Petrarca (6.45-50), etc. En la literatura castellana será reelaborado en el Orfeo de Jáuregui: «Ya ve delante el Sueño, la Tristeza, / el de pálida tez lánguido Morbo, / la Guerra atroz, las Scilas, i Chimeras, / i otras de el Orco antecedentes Fieras» (2.85-88).

22 Este lugar divino se denomina posteriormente «politico Eliseo» (Pelayo 11, f.153r), una nueva alusión al más allá grecolatino. 
Tiene dos puertas el Cymerio polo

Hechas de cuerno luzido, y de diente (...).

Dexa Pelayo a izquierda las Cymeras

Puertas formadas con eburneos die[n]tes,

Abiertas para ensueños y quimeras,

Y cosas que no son mas que aparentes:

Y guia a las que dan las vedrieras,

Y laminas de cuernas trasparentes:

Salida para imagines de cosas,

Que huyeron de las hojas fabulosas.

Tanto el detalle de la marcha del guía al alba como el de las puertas acentúan el carácter onírico de la aventura de ultratumba. El guía, por su estrecho vínculo con el sueño $^{23}$, desaparece de este inframundo sui generis con las primeras luces del día. Ya desde Homero los sueños y la muerte estaban estrechamente relacionados, pues se ubica el país de los Sueños junto al Hades (Od.24.12), por lo que ambos reinos estarían conectados. También las puertas descritas por el Pinciano tienen su origen en la Odisea. Según el poeta griego existen dos puertas, la de cuerno, por la que salen los sueños verídicos, y la de marfil, destinada a los falsos (Od.19.562-567):

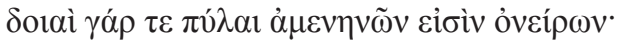

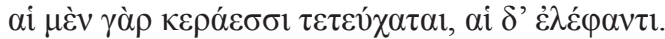

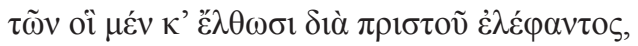

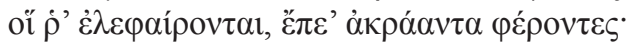

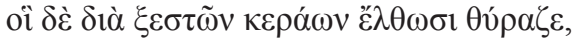

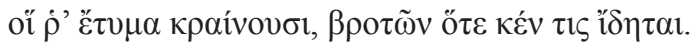

Dos puertas hay de los leves sueños:

Una fabricada con cuerno, la otra con marfil.

Los que llegan a través del engastado marfil,

esos engañan, portando palabras no cumplidas;

los que llegan fuera a través de cuernos pulidos,

esos anuncian cosas verdaderas cuando algún mortal los ve.

Virgilio reelabora el pasaje homérico y hace de la puerta de marfil el lugar apropiado para la salida de Eneas del inframundo (Aen.6.893-898):

Sunt geminae Somni portae, quarum altera fertur

cornea, qua ueris facilis datur exitus umbris,

altera candenti perfecta nitens elephanto,

sed falsa ad caelum mittunt insomnia Manes.

23 En el libro décimo el ser metamórfico recibe muy diversas denominaciones relacionadas con el mundo de ultratumba (alma, sombra, cimérico), con su habilidad metamórfica (el Vertumno, el Proteo) o con su rol de acompañante (huésped, guía, guion), pero nunca se nos indica su nombre. Sin embargo, en el libro undécimo, una vez que este ser se ha ido, Pelayo medita sobre las cosas que «dentro del politico Eliseo / Dixo el sapiente y prouido Morfeo» (f.153r), lo que quizá permitiría su identificación con el hijo del Sueño. 
his ibi tum natum Anchises unaque Sibyllam prosequitur dictis portaque emittit eburna...

Hay unas puertas gemelas del Sueño, de las cuales una, se dice, es de cuerno, por la que se concede fácil salida a las sombras verdaderas, la otra, brillante, está fabricada con albo marfil, pero por allí al cielo envían falsos ensueños los manes.

Entonces Anquises a su hijo junto a la Sibila acompaña conversando y los despide por la puerta ebúrnea...

Estos versos fueron utilizados como base para argumentar que el viaje de Eneas al mundo de los muertos era en realidad un sueño ${ }^{24}$. López Pinciano, que enfatiza la naturaleza onírica de la aventura, incluye en el más allá la puerta de marfil, una nueva marca de que el episodio debe ser interpretado en clave alegórica.

Además, el Pinciano introduce una innovación. Entre ambas puertas se alza un postigo intermedio, aleación de marfil y cuerno (Pelayo 11, f.152r):

Entre la puerta Cornea, y vedriera, Y entre la otra del escuro diente Tiene un breue postigo la Cymera, $\mathrm{q}[$ ue $]$ al Ebur mezcla el cuerno trasparente.

Por cada uno de estos vanos salen diversas agrupaciones de personajes, mediante los cuales López Pinciano acentúa el contenido alegórico del episodio a la vez que plasma poéticamente la doctrina sobre la épica expresada en su Filosofía antigua poética.

En el Pelayo el caudillo observa cómo salen de la puerta de marfil algunos de los principales dioses, divinidades y héroes del panteón grecolatino ${ }^{25}$. Este catálogo, destinado a ofrecer una selección de la mitología clásica, sienta la postura de López Pinciano acerca del uso de la religión pagana en un nuevo contexto cultural. En la Filosofía se establece que el poeta debe mantener la verosimilitud con la cultura a la que pertenece. Es verosímil que en las obras de Homero y Virgilio aparezcan dioses paganos. Sin embargo, se condena explícitamente el uso de la religión clásica en obras cristianas $(5$, p.67):

Y porque entonces los poetas escriuieron cosas verisímiles en su falsa religión no enfadan agora ni enojan a los lectores: lo qual harían los cristianos poetas, porque dirían mentiras muy descaradas, si siguiessen la tal religión ${ }^{26}$.

24 Juan Luis de la Cerda, humanista contemporáneo de López Pinciano, en sus comentarios a la Eneida apunta a tenor de este pasaje que ya desde antiguo se consideraba que Virgilio quería indicar con estos versos que el relato del viaje al mundo de los muertos de la Eneida era falso, una mera ensoñación (Aen. 6. 893, nota 3).

25 La enumeración comienza con el Cielo, Ops, Vesta, Júpiter y Titán. Son los dioses partícipes del mito de sucesión según la versión de Ennio en Evemero: Saturno, hijo del Cielo y de Vesta, se unió a Ops y obtuvo el reino sobre las pretensiones de su hermano Titán, con la condición de que matase a sus hijos. Pero, nacido Júpiter, fue criado en secreto por Vesta y posteriormente vencería a Titán y derrocaría a Saturno. La obra de Ennio no se ha conservado, pero este pasaje fue transmitido por Lactancio en Instituciones Divinas (1.13) a fin de demostrar que los dioses paganos eran realmente hombres mortales. También se recoge en el comentario realizado a las Trescientas de Juan de Mena por Hernán Núñez de Guzmán (glosa a la copla 232). López Pinciano conocía este comentario, pues lo cita en la Filosofía antigua poética (6, pp.160-161).

26 Nos servimos de la edición de Carballo Picazo (1973). Consta de tres tomos, que contienen respectivamente las 
Precisamente, el presente artículo tiene el objetivo de analizar cómo el Pinciano se sirve de la mitología grecolatina para ambientar el viaje al más allá de un héroe cristiano. ¿Está el vallisoletano rompiendo su propia norma ${ }^{27}$ ? Él mismo explica cómo la verosimilitud puede ensancharse mediante la alegoría. Se pueden describir cosas fantásticas siempre que se realicen de manera simbólica $(5, \mathrm{pp} .64-65)$ :

¿Qué semejanza a verdad tiene Homero, quando en su Vlysea dize que los bueyes del Sol hechos pedaços y en los asadores bramaua $[n]$ al fuego? (...) ¿Y qué también Virgilio, quando dize que las naues de Eneas, quemadas, se conuirtieron en nimphas? (...) A esta objeción respondiera Plutarcho, y aun Aristóteles, que la alegoría es la causa basta $[n]$ te para lo poder hazer.

Más adelante añade que la imitación puede ser superada por la alegoría, debido al importante efecto intelectual y moral que esta favorece (5, pp.94-95):

Fadrique dixo: A mí place; y será muy breue, mas por el qual se entienda esta doctrina muy bien. Alegoría segunda y principal es dicha la significación produzida de otra cosa, la qual es secreta y escondida al vulgo, y manifiesta sólo a los hombres doctos (...).

El Pinciano se dió vna palmada en el pecho y dixo; Yo entiendo esto de la alegoría, y por vna doctrina semejante no me parece mal que se pierda la imitación.

En cualquier caso, la epopeya perfecta es aquella que aúna verosimilitud y alegoría (5, pp.96; 11, pp.222-223). Esto es lo que López Pinciano aspira a lograr en el viaje al mundo de los muertos del Pelayo. Aunque denominaciones como el Leteo o Cimeria nos introducen en un Hades grecolatino, las frecuentes marcas de que Pelayo está experimentando un sueño, como la ya mencionada sustitución de los jueces infernales clásicos por los hijos de Hipnos, potencia la naturaleza onírica del episodio y, en consecuencia, su lectura simbólica. Es más, al hacer salir por la puerta de las visiones falaces a los dioses grecolatinos, se remarca la falsedad de la religión pagana. Esto, unido a los detalles antes expuestos, muestra que la aventura esconde bajo su superficie mítica un contenido cristiano.

Los dioses grecolatinos no son los únicos seres que salen por la puerta de marfil. Se incluye también una enumeración de personajes literarios, en particular los de algunos de los romanzi y las novelas de caballerías más relevantes en la época de López Pinciano ${ }^{28}$. Se declara así el carácter ficcional de estos héroes, en oposición a

epístolas 1-4, 5-8 y 9-13. Citamos por el número de epístola y la página del tomo correspondiente.

27 Hay otra ocasión en la que personajes míticos grecolatinos participan en la acción. En el libro primero Pelayo llega a Chipre sobre un delfín, acompañado de nereidas y tritones, lo que simbolizaría el favor del mar. Después relata ante la realeza chipriota su recibimiento por el dios marino en el fondo abisal. Este relato se introduce con fórmulas como «Y narrale tambien cosas de menos / Credito...» (1, f.15r) o «Y Cuentale tambien (si es que la fama / Conforma la verdad con el oydo)...» (1, f.15v), posible indicio de que el relato es fantástico. Es más, entre las divinidades que salen por la puerta de marfil se nombra a «toda la estirpe de Nereo» $(11, \mathrm{f} .151 \mathrm{v})$, es decir, las nereidas, por lo que el propio López Pinciano declara la ficcionalidad de estas ninfas y la consecuente necesidad de realizar una interpretación alegórica de su ayuda a Pelayo en el libro primero.

28 De romanzi como Orlando enamorado y Orlando furioso o de novelas de caballerías como Amadís de Gaula, Espejo de príncipes y caballeros, Valerián de Hungría, Primaleón, Palmerín de Oliva, Olivante de Laura o Belianis de Grecia, entre otros. 
las personalidades históricas que atraviesan la puerta de cuerno. Se plasma de nuevo artísticamente la doctrina literaria del autor. En efecto, en la Filosofía antigua poéti$c a$ se afirma que las novelas de caballerías pertenecen por completo al género épico, aunque sus personajes no hayan existido, por lo que carecen de contenido histórico (11, pp.165-166). Con todo, se constata la superioridad de la épica histórica respecto a la epopeya fantástica («tiene más perfección la épica fundada en historia que no en ficción pura», 11, p.167).

En consecuencia, mientras que los personajes fabulosos son vinculados con la puerta de la ficción, las personalidades históricas, más aptas para la epopeya, salen por la de cuerno, ya que son reales. Pelayo tiene ocasión de observar «mil sombras de linage peregrino, / Ideas y trasumptos de Regentes, / Que fueron, o seràn, o son presentes» (Pelayo 11, f.153r). Se trata de un vasto catálogo de reyes ordenados cronológicamente y agrupados según el territorio gobernado, desde los faraones egipcios hasta los reyes godos, sin olvidar a los monarcas helenísticos y los emperadores romanos $^{29}$.

Como se ha podido apreciar en estas páginas, uno de los principales componentes del viaje al más allá de Pelayo es el catálogo o enumeración de espíritus. La mayor parte del episodio consiste en la observación por parte del héroe de una serie de condenados, bienaventurados, divinidades, personajes, escritores y reyes. El último catálogo, el de regentes, es el más extenso y elaborado de todos. Se trata de un elemento literario clásico y característico del tema, que, al favorecer la convergencia en un mismo punto de referentes muy alejados tanto temporal como espacialmente, constituye un importante recurso de alabanza del protagonista mediante su asociación con figuras prestigiosas. Esta especial significación heroica tiene su origen en la Nékyia, en la que priman las enumeraciones de las almas observadas por Odiseo (héroes y heroínas). A partir de estos catálogos se creaba el trasfondo mítico de la aventura y se magnificaba la figura del protagonista al hacerlo partícipe y miembro del conjunto de grandes personalidades de la mitología griega. Virgilio retoma el uso del catálogo de almas con una interesante innovación. Eneas no solo observa difuntos del pasado, sino también las almas que se van a reencarnar en los gobernantes romanos del futuro $^{30}$. De esta manera, se ensalzaba la vertiente histórica de Eneas como ancestro de los grandes dirigentes de la potencia latina. A partir de los dos modelos clásicos este tipo de catálogos gozó de una gran tradición en la literatura occidental. Uno de sus máximos exponentes es la Divina Comedia de Dante, repleta de catálogos de difuntos y otros seres, desde Homero hasta la época del autor. En particular, destacan los catálogos de monarcas europeos del pasado reciente (Purgatorio 7) y del futuro (Paraíso 19), de inspiración virgiliana. Posteriormente, en el tercer canto del Orlan-

29 El catálogo responde al concepto de translatio imperii, el paso de la hegemonía imperial de una nación a otra, de Oriente a Occidente, hasta culminar en España (Vilà 2005b, p. 78).

30 El catálogo de gobernantes pasados del Pelayo se completa en el canto décimo tercero. El caudillo se interna en otra gruta, la de Covadonga, donde Uriel enumera los reyes que lo sucederán, desde Favila hasta Felipe III, contemporáneo de López Pinciano. Antes de este catálogo, durante la aparición del arcángel hay una posible alusión a Anquises. Al vislumbrar a Uriel en la cueva, Pelayo rememora «de la Creusa Troyana la alma suegra» (12, f.184r). Puesto que Creusa era la esposa de Eneas, la referencia hace alusión a Venus o a Anquises. En este caso, se trata posiblemente de una marca de hipertextualidad que conecta al arcángel con el padre de Eneas, pues ambos desarrollan un rol similar. El alma de Anquises explicó a su hijo en el más allá un catálogo de futuros gobernantes romanos (Aen. 6.756-886) de la misma manera que Uriel en la cueva vaticina a Pelayo los gobernantes hispanos venideros. 
do furioso de Ariosto se profetiza a Bradamante dentro de una cueva encantada una enumeración de descendientes llegados del más allá y en el noveno de la Italia Liberada de Trissino el general Belisario observa en el otro mundo bajo la forma catalogada a un gran número de almas (literatos de la Antigüedad, personajes de la Iliada, gobernantes y emperadores romanos o europeos, etc.). No faltan tampoco ejemplos en España. En el Infierno de los enamorados del Marqués de Santillana se desarrolla un catálogo de condenados de amor, la mayoría clásicos (53-66). El Laberinto de la Fortuna, un viaje alegórico al más allá escrito por Juan de Mena, está repleto de catálogos, con personajes clásicos y dirigentes romanos, también en la estela de Virgilio. Este mismo autor relata en la Coronación un nuevo viaje al más allá compuesto de catálogos de condenados clásicos, de mujeres castigadas o de grandes escritores (p. ej. Homero y Virgilio) cuyo fin es ensalzar al Marqués de Santillana. Como vemos, cuando López Pinciano recrea en el Pelayo su viaje alegórico al más allá a partir de la sucesión de enumeraciones de almas pasadas y futuras, de pecadores, escritores y gobernantes, se asienta con firmeza sobre una sólida tradición occidental de raíz grecolatina. Si el descenso en el libro décimo comienza y finaliza con una profecía que adelanta la descendencia regia de Pelayo, en el ascenso del libro undécimo se repasa la tradición de la que el héroe formará parte, la de los monarcas de las grandes potencias históricas. Ahora le toca a España tomar el relevo imperial.

Queda por último el original postigo intermedio. Su cualidad mixta, entre la ficción y la realidad, nos remite al citado concepto de la teoría literaria del Pinciano, la verosimilitud, base de la actividad poética (Filosofía antigua poética 5, pp.97-98):

El campo de la Poética es inmenso, dize Ouidio, y a ninguna historia es obligado; que es dezir: el poeta no es obligado a la verdad más de quanto le parece que conuiene para la verisimilitud; lo qual especialmente vsan los trágicos y épicos prudentíssimamente en general para hazer su narración más verisímil, y con algunas verdades como rafas tener firme la tapiería de sus ficciones. Todo esto se haze para el fin que está dicho, que es el deleyte y la doctrina. Assí que los poemas que sobre historia toman su fundamento son como vna tela cuya vrdimbre es la historia, y la trama es la imitación y fábula.

Los poetas combinan en su obra realidad y ficción. No es de extrañar, por tanto, que por el postigo intermedio, aquel que participa a su vez del falso marfil y del cuerno verdadero, salga una procesión de artesanos de la verosimilitud, los escritores. Encabezan la marcha los dos grandes modelos de la epopeya, Homero y Virgilio. Según el Pelayo, Homero, aun obligado a mendigar, es el primero de los cantores $(10, f .152 r)^{31}$, y junto a él marcha Virgilio, con el resto de los poetas a gran distancia $(10$, f.152v). Son seguidos por Quinto de Esmirna («el Calabro»), Estacio, Ovidio y Lucano, mientras que se alude al resto de manera ambigua ${ }^{32}$. Solo se da el nombre

31 En la Filosofia se relata la sorpresa de López Pinciano por la alta fortuna de Homero, a pesar de haber sido pobre y ciego: «el Pinciano se fué, muy admirado, a su posada, de que vn hombre como Homero, escuro, pobre, ciego y que murió de necio, fuesse el más feliz de la tierra» (1, p.138).

32 «Es vno que de Grecia otro que de Esperia / Cantan los Heroes con heroica lira» (11, f.152v). Se menciona también a «Alpino, cuchillo de Menona el Matutino». Este Alpino es citado también en la Filosofía: «de Alpino poeta se dize que degolló á Memnón, hijo de la Aurora, porque escriuió dél baxamente y con estilo plebeyo» (6, p.171). En ambos casos, la referencia parece tomada de las Sátiras de Horacio, donde se dice que «el ampuloso Alpino degüella a Memnón» (turgidus Alpinus iugulat dum Memnona, 1.10.36). Este tal Alpino sería posible- 
de estos escritores grecolatinos, si bien a ellos se suman de manera genérica otros «autores que no eran / Venidos en el mundo mas se esperan». Como en el catálogo de almas de la Eneida, en el más allá del Pelayo se puede observar a las ánimas del futuro ${ }^{33}$.

El encuentro con escritores del pasado, normalmente en forma catalogada, es común en el tema del viaje al mundo de los muertos. El autor se adscribe así a una determinada tradición literaria. Horacio se encuentra en el inframundo con Safo y Alceo (Carm.2.13); Silio Itálico hace que Escipión y la Sibila miren admirados a Homero (SIL.13.781-797); Dante, acompañado por Virgilio, es acogido en el Limbo por Homero, Horacio, Ovidio y Lucano (Divina Comedia, Infierno 4.85-102); en la Coronación el Marqués de Santillana es laureado entre los grandes escritores (Salomón, David, Aristóteles, Homero, Lucano, Virgilio, Séneca, Ovidio, etc.). De manera similar, el Pinciano muestra en el viaje al más allá los eslabones de la tradición épica de la que forma parte, a la vez que refleja la técnica compositiva de estos escritores, basada en la verosimilitud y la alegoría. López Pinciano, como sus antecesores, ha atravesado el postigo intermedio al componer una epopeya que aúna la fantasía alegórica y la verdad histórica. En la Filosofía antigua poética, al teorizar sobre tales cuestiones, se concedía esta cualidad intermedia a la historia de Don Pelayo, que, por tanto, se juzga óptima para la más elevada clase de epopeya (10, pp.168-170):

y si, digo otra vez, huuiera de escriuir heroyca, tomara por subjeto al infante don Pelayo, cuya historia tiene todas las calidades que deue tener la que ha de dar materia a la heroyca (...). La historia es admirable, y ni tan antigua que esté oluidada, ni ta $[n]$ moderna que pueda dezir nadie «esso no passó ansí»; y esta es otra condición que deue tener la buena épica (...). Que, allende de lo dicho, la historia de Pelayo es muy aparejada para la épica porq[ue] es breue, y no de tal manera ocupará los papeles del poema, que el poeta pierda lugar para la imitación...

El Pinciano expresa su deseo de llevar a cabo esta empresa (10, p.170):

Y el Pinciano: Yo lo hiziera, principalmente porque el subjeto es digno de épica, y por afición que le tengo desde mi niñez...

El viaje al más allá del Pelayo muestra cómo López Pinciano ha llevado a la práctica sus postulados teóricos sobre la epopeya. Para dotar al episodio de verosimilitud geográfica el poeta vallisoletano sigue la descripción de Pomponio Mela. Pero pronto el paisaje, mediante el artificio de una experiencia onírica, se transforma en un lugar místico, a partir de la adaptación de detalles ovidianos de la morada del Sueño y las características de sus hijos. En este más allá de ensueño el héroe Pelayo sigue la estela de sus referentes clásicos y emula el patrón narrativo del viaje al mundo de los muertos. De esta manera, el caudillo asturiano acomete la mayor aventura del héroe épico, por lo que demuestra su óptima calidad heroica. Pero Pelayo se presenta fundamentalmen-

mente M. Furio Bibáculo, cuyo apelativo derivaría de una grandilocuente descripción de los Alpes que habría incluido en su epopeya sobre la Guerra de las Galias. También se considera artífice de un poema sobre la muerte de Memnón, no muy valorado por Horacio.

33 Incluso se pueden observar almas del presente. Aunque se sigue el patrón de un viaje al mundo de los muertos, el de Pelayo es un viaje onírico y, como sueño fantástico, no tiene apenas limitaciones creativas. 
te como el adalid hispano del cristianismo. Por ello, sirviéndose de la gran capacidad referencial de la aventura, el caudillo es asociado con los grandes reyes del pasado, de los que entrará a formar parte como origen del imperio español. A su vez, tanto los catálogos de condenados y bienaventurados, pertenecientes al cristianismo, como ciertas marcas diseminadas en el texto, apuntan a la necesidad de realizar una lectura alegórica del episodio que recolecte la esencia cristiana entre la urdimbre pagana.

En suma, López Pinciano ha creado un episodio complejo, con múltiples capas de interpretación. La primera es el resultado de la combinación y armonización de fuentes y modelos grecolatinos; en ella el poeta muestra su erudición clásica a través de la adaptación de patrones, detalles y motivos de la literatura de la Antigüedad. La interpretación alegórica da acceso a otro nivel en el que mediante múltiples detalles y exempla de pecados y virtudes se desarrollan concepciones morales acerca de las características del buen y el mal cristiano. Por último, subyace también una lectura metaliteraria; el Pinciano simboliza con las tres puertas del más allá los postulados relativos a la épica que él mismo ha seguido en la composición del episodio y del conjunto del Pelayo. El resultado es una aventura de gran originalidad y una muestra representativa de aplicación del humanismo a la creación poética.

\section{Bibliografía}

Anderson, W. S. (1962), Ovidius, Metamorphoses, Leipzig, Teubner.

Carballo Picazo, A. (1973), López Pinciano, Philosophia antigua poetica, tomos I-III, Madrid, CSIC.

Cebrián García, J. (1989), «El género épico en España: de los poemas mayores al canto épico», Philologia hispalensis 4.1, 171-184. DOI: 10.12795/PH.1989.v04.101.14

Frick, C. (1880), Pomponii Melae De Chorographia libri tres, Stuttgart, Teubner.

Frutos Martínez, M. C. de (1999), «Alusiones a la literatura italiana en la Philosophia antigua poética de López Pinciano», en Couceiro Pérez, X. L. et alii (coord.), Homenaxe ó profesor Camilo Flores II: Literaturas especificas, Santiago de Compostela, Universidade, 335-347.

González Álvaro, M. ${ }^{a}$ L. (1997), «Homero en la teoría literaria española del Siglo de Oro», EHum 19, 33-50. DOI: 10.18002/ehf.v0i19.4055

Guzmán Arias, C. (1989), Pomponio Mela. Corografia, Murcia, Secretariado de Publicaciones de la Universidad de Murcia.

Lara Garrido, J. (1982), «Teoría y práctica de la épica culta en el Pinciano. Lectura de la Philosophia antigua poética y del Pelayo desde el canon tassiano», Revista de Literatura 44.88, 5-56. Reimpreso en Lara Garrido, J. (ed.) (1999), Los mejores plectros. Teoría y práctica de la épica culta en el Siglo de Oro, Málaga, Universidad de Málaga, 395-454.

Linares Sánchez, J. J. (2020), El tema del viaje al mundo de los muertos en la Odisea y su tradición en la literatura occidental, Murcia, Editum.

Maldonado Araque, F. J. (2010), «La determinación clásica en la Philosophia Antigua Poetica de Alonso López Pinciano: anclaje medieval y proyección renacentista», Myrtia 25, 243-258. <https://revistas.um.es/myrtia/article/view/131671> [01/05/20]

Menéndez Pelayo, M. (1940), Historia de las ideas estéticas en España, tomo II, Siglos XVI y XVII, Santander, CSIC. <http://www.larramendi.es/menendezpelayo/es/corpus/unidad. do?idCorpus $=1000 \&$ idUnidad $=100033 \&$ posicion $=1>[03 / 12 / 20]$ 
Mynors, R. A. B (1972), P. Vergili Maronis Opera, Oxford, Clarendon Press.

Shepard, S. (1970² [1962]), El Pinciano y las teorías literarias del Siglo de Oro, Madrid, Gredos.

Vilà, L. - Esteve, C. (eds.) (2005), López Pinciano. Alonso. El Pelayo. Estudios introductorios de Lara Vilà y Cesc Esteve, Vigo, Mirabel. <http://hdl.handle.net/10016/18670> $[01 / 05 / 20]$

Vilà, L. (2005a), «Estudios Preliminares», en Vilà, L. - Esteve, C. (2005).

Vilà, L. (2005b), «Épica, reconquista y alegoría política: el Pelayo de Alonso López Pinciano», Salina: revista de lletres 19, 75-82. <http://www.cervantesvirtual.com/nd/ ark:/59851/bmc4q9w2> [01/05/20]

Vilà, L. (2006), «Épica, historia y la construcción de los mitos nacionales. La problemática de la teoría y la praxis de la épica culta en el siglo XVI (en Italia y España)», História \& Perspectivas 34, 83-106. <http://www.seer.ufu.br/index.php/historiaperspectivas/article/ view/19036> [01/05/20]

Vilà, L. (2007), «Los Poemas de la fundación nacional. La épica del siglo XVII y la idea del imperio», Conceptos: Revista de Investigación Graciana 4, 53-67. <http://hdl.handle. net $/ 2183 / 17920>[01 / 05 / 20]$

Vilanova, A. (1953), «Preceptistas españoles de los siglos XVI y XVII», en Díaz Plaja, G. (ed.), Historia general de las literaturas hispánicas, tomo III, Renacimiento y Barroco, Barcelona, Barna, 565-692.

von der Mühll, P. (1962³ [1946]), Homeri Odyssea, Stuttgart, Teubner. 